\title{
Astrocyte-Mediated Hepatocyte Growth Factor/Scatter Factor Supplementation Restores GABAergic Interneurons and Corrects Reversal Learning Deficits in Mice
}

\author{
Gregory B. Bissonette, ${ }^{1,2}$ Mihyun H. Bae, ${ }^{1}$ Tejas Suresh, ${ }^{1}$ David E. Jaffe, ${ }^{1}$ and Elizabeth M. Powell ${ }^{1,2,3}$ \\ ${ }^{1}$ Department of Anatomy \& Neurobiology, ${ }^{2}$ Program in Neuroscience, and ${ }^{3}$ Department of Psychiatry, University of Maryland School of Medicine, \\ Baltimore, Maryland 21201
}

\begin{abstract}
Many psychiatric and neurological disorders present persistent neuroanatomical abnormalities in multiple brain regions that may reflect a common origin for a developmental disturbance. In mammals, many of the local GABAergic inhibitory interneurons arise from a single subcortical source. Perturbations in the ontogeny of the GABAergic interneurons may be reflected in the adult by interneuron deficits in both frontal cerebral cortical and striatal regions. Disrupted GABAergic circuitry has been reported in patients with schizophrenia and frontal lobe epilepsy and may contribute to their associated impairments in behavioral flexibility. The present study demonstrates that one type of behavioral flexibility, reversal learning, is dependent upon proper numbers of GABAergic interneurons. Mice with abnormal interneuron ontogeny have reduced numbers of parvalbumin-expressing GABAergic local interneurons in the orbitofrontal cortical and striatal regions and impaired reversal leaning. Using a genetic approach, both the anatomical and functional deficiencies are restored with exogenous postnatal growth factor supplementation. These results show that GABAergic local circuitry is critical for modulating behavioral flexibility and that birth defects can be corrected by replenishing crucial growth factors.
\end{abstract}

\section{Introduction}

In schizophrenia and frontal lobe epilepsy, the age of onset reflects a developmental origin, with disruptions in GABAergic neuron ontogeny as a possible cause (Porter et al., 2002; Tamminga et al., 2004; Hashimoto et al., 2008). During embryogenesis, forebrain GABAergic neurons are generated subcortically, and interneurons migrate to the cerebral cortex, hippocampus, amygdala, and olfactory bulbs, while the medium spiny projection neurons and local interneurons remain in the striatum (Anderson et al., 1997, 2001; Marin et al., 2000; Letinic et al., 2002; Nery et al., 2002). Studies in transgenic mice report that perturbations in GABAergic ontogeny lead to anatomical deficits and abnormal behaviors, similar to those found in human psychiatric and neurological disorders (Stork et al., 2000; Powell et al., 2003; Cobos et al., 2005).

Multiple molecules contribute to the ontogeny of the cerebral cortical GABAergic interneurons (for review, see Wonders and Anderson, 2006). In particular, transgenic mice lacking the urokinase plasminogen activator receptor (Plaur) have selective loss of GABAergic interneurons in anterior cingulate and so-

Received 0ct. 23, 2009; revised Dec. 29, 2009; accepted Jan. 5, 2010.

This study was supported by a National Alliance for Research on Schizophrenia and Depression Young Investigator Award (E.M.P.), an Epilepsy Foundation Predoctoral Fellowship (M.H.B.), and National Institutes of Health Grant R01 DA018826 (E.M.P.). We are grateful to Dr. Cristian Achim for the HGF mice. We thank Drs. Gabriela Martins, Geoff Schoenbaum, Patricio $0^{\prime}$ Donnell, and Dalila Akkal for comments on early versions of the manuscript.

Correspondence should be addressed to Dr. Elizabeth M. Powell, Department of Anatomy \& Neurobiology, University of Maryland School of Medicine, HSF II S251, 20 Penn Street, Baltimore, MD 21201. E-mail: epowe001@ umaryland.edu.

DOI:10.1523/JNEUROSCI.5268-09.2010

Copyright $\odot 2010$ the authors $\quad 0270-6474 / 10 / 302918-06 \$ 15.00 / 0$ matosensory cortical areas (Powell et al., 2003). These defects are specific for the parvalbumin-expressing $\left(\mathrm{PV}^{+}\right)$GABAergic interneuron subtype, whereas neurons expressing the somatostatin and calretinin markers are unaffected (Powell et al., 2003; Eagleson et al., 2005). The cerebral cortical $\mathrm{PV}^{+}$interneuron populations are fast-spiking cells that are reported to be reduced in human epilepsy and schizophrenia (Ferrer et al., 1994; Beasley and Reynolds, 1997; Hashimoto et al., 2008). Therefore, the Plaur-null mice display anatomical deficits observed in human disorders.

Previous reports have demonstrated that Plaur mice have grossly normal sensory and motor function, as well as exploratory behavior (Powell et al., 2003). Plaur mice displayed increased anxiety, as measured by the light-dark avoidance and elevated plus maze tests. The localized interneuron defects in the Plaur mice suggest that behaviors relying on the frontal cortex may be impaired. One method of evaluating prefrontal cortical function is reversal learning, which is a measure of behavioral flexibility or ability to adapt to the changing environment. In primates and rodents, reversal learning is dependent upon intact orbitofrontal cortex (OFC) and dorsal striatal regions (Dias et al., 1996a; McAlonan and Brown, 2003; Brigman et al., 2005; Bissonette et al., 2008). Local inhibitory circuitry for the OFC and striatum is provided by the GABAergic interneurons that arise embryonically, and interruptions in ontogeny are predicted to impair reversal learning. This study tests the hypothesis that the GABAergic interneuron deficits in the Plaur mice extend to the OFC and striatal regions and correlate with impaired performance on a reversal learning task.

In the absence of Plaur, reduced levels of hepatocyte growth factor/scatter factor (HGF/SF) and of its receptor Met appear to 
limit embryonic cell migration and survival (Powell et al., 2001; Bae et al., 2010). Thus, postnatal supplementation of HGF/SF may prevent the GABAergic interneuron loss and rescue the functional deficits. In this report our data demonstrate a role for parvalbumin-expressing GABAergic interneurons in reversal learning, and a possible mechanism to correct deficits in neuropsychiatric disorders.

\section{Materials and Methods}

Animals. C57BL/ $6^{\mathrm{J}}$ mice were purchased from The Jackson Laboratory. The B6.129- $\mathrm{Tg}(G f a p-H G F)^{\mathrm{Ca}}$ (abbreviated as HGF) mice, in which the expression of human HGF is under the regulation of the glial fibrillary acidic protein (GFAP), and B6.129-Plaur ${ }^{\text {tmI/Mlg}} /$ Plaur $^{\text {tml/Mlg }}$ mice lacking the gene that encodes the urokinase plasminogen activator receptor (UPAR) protein (abbreviated as Plaur) were generous gifts from our collaborators C. Achim (University of California, San Diego, La Jolla, CA) and P. Carmeliet (Center for Transgene Technology and Gene Therapy, Flanders Interuniversity Institute for Biotechnology, KU Leuven, Leuven, Belgium), respectively (Dewerchin et al., 1996). All research procedures using mice were approved by the Institutional Animal Care and Use Committee at University of Maryland and conformed to National Institutes of Health guidelines. The HGF mice were genotyped via PCR using the following primer sets: $5^{\prime}$-ggCCATgAATTTgACCTCTATgAA-3' and 5' -TTCAACTTCTgAACACTgAggAAT-3' (250 bp) for Gfap-HGF mice, and 5'-CCTCATCCTgggCCTggTTCTggTCT- $3^{\prime}$ and $5^{\prime}$-ggTTTTCCCCgCTgTggTCATCTgC-3' (200 bp) as a positive control. For genotyping Plaur mice, the primer sets were as follows: 5'-gATgATAgAgAgCTggAggTggTgAC-3' and 5'-CACCgggTCTgggCCTgTTgCAgAggT-3' (145 bp) for Plaur, 5' -ATTgAAgAAgATggATTgCAC-3' and 5'-TTCgTCCAgATCATCCTgATCgAC-3' (500 bp) for neomycinresistant gene. Behavioral and anatomical analyses were performed on adult male littermates from at least 4 separate pedigrees. B6.129 male wild-type (WT) littermate mice were used as controls. All mice were bred from heterozygotes that had been backcrossed onto the C57BL/6J (B6) background for $>10$ generations.

Immunohistochemistry. The mice were transcardially perfused with buffered $2 \%$ paraformaldehyde, $2 \%$ glutaraldehyde, and $0.2 \%$ picric acid fixative, and the brains were postfixed overnight at $4^{\circ} \mathrm{C}$. Vibratome sections $(50 \mu \mathrm{m})$ were cut and stained using routine laboratory protocols (Powell et al., 2003; Martins et al., 2007). The sections were incubated with mouse anti-parvalbumin antibodies (1:1000, Sigma Chemical), followed by biotin-conjugated donkey anti-mouse secondary antibodies (1:2000, Jackson ImmunoResearch). Images were obtained by Leica DMRX microscope (Leica Microsystems) with Phase One image capture software version 3.04 (Phase One).

Cell counting and analysis. The numbers of PV-immunoreactive cells were estimated in individual brain regions by blinded observers using the Neurolucida system (MicroBrightField). For each region, at least 3 brains for each genotype were analyzed. Unbiased stereological cell counts were obtained sections spaced $400 \mu \mathrm{m}$ apart from 2 sections in orbitofrontal cortex [OFC; from bregma level $2.86 \mathrm{~mm}$ extending caudally to $2.20 \mathrm{~mm}$ (Paxinos and Franklin, 2001)], and 5 sections along the striatum (bregma level $=1.54 \mathrm{~mm}$ and extending caudally to $-1.06 \mathrm{~mm}$ ) (West, 1999). A dissector of $100 \mu \mathrm{m} \times 100 \mu \mathrm{m}$ was used for cortical regions and of 350 $\mu \mathrm{m} \times 350 \mu \mathrm{m}$ for striatal and amygdalar interneurons. Volume was estimated using the Cavalieri method (Howard and Reed, 1998). Data are provided as mean \pm SEM, from at least 3 mice for each genotype. The statistical significance among four different genotypes was examined using one-way ANOVA followed by Newman-Keuls post hoc analysis (Statistica version 8 , StatSoft).

Reversal learning task. A reversal task was performed as described in previous reports (Colacicco et al., 2002; Bissonette et al., 2008). Food deprived mice were trained to dig in bowls of scented media to retrieve cereal rewards. At the start of each trial, the mouse was placed in the testing arena to explore two bowls with combinations of odors and digging media until digging in one bowl to signify a choice. The bait was a piece of Honey Nut Cheerio cereal ( $\sim 5 \mathrm{mg})$, and the cues, either olfactory (odor) or somatosensory and visual (texture of the digging medium that hides the bait) were altered and counterbalanced. All cues were presented in identical small animal food bowls (All Living Things Nibble Bowls, PetSmart) that were identical in color and size. Digging media was mixed with the odor $(0.01 \%$ by volume $)$ and Honey Nut Cheerio powder $(0.1 \%$ by volume). Odors (ground dried spices) and unscented digging media are listed in supplemental Tables 1 and 2 (available at www. jneurosci.org as supplemental material). The mice were housed in Softcard bedding. The digging media did not contain any components used in the animal bedding. On the first day of training, the mice were given 4 consecutive trials with the baited food bowl to ascertain they could reliably dig. All mice were able to dig for the reward.

Mice were tested through a series of discriminations where the exemplar pair was changed, but the dimension (odor or medium) of the correct choice remained the same. The dimension was relevant if its attributes predicted outcome. For example, if odor was the relevant dimension, then the mouse was required to choose the correct odor from each pair and ignore the attributes of the digging medium. In this example, the digging medium is considered the irrelevant dimension. The tests used are as follows: (1) a single series of simple discriminations (SD) in which the mouse was presented with two choices of the relevant dimension and one choice of the irrelevant dimension (i.e., two odors within the same medium); (2) a single series of compound discrimination (CD) in which the mouse was presented with the same choices of relevant dimension as in the SD and two choices of irrelevant dimensions (the exemplar used in the SD and a new exemplar); (3) an intradimensional shift (IDS I-IV) in which the mouse was presented with compound discriminations using two novel exemplars from the relevant and irrelevant dimensions for each IDS [The relevant dimension of the correct choice (i.e., odor) was maintained throughout the discriminations.]; and (4) a reversal discrimination (IDSrev) in which the mouse was presented with the same set of exemplars as in the IDS, but the stimulus-reward pairing was reversed within the relevant dimension.

The baited bowl was randomly presented on either side of the testing cage, and the relevant exemplar was randomly presented with the irrelevant exemplars. The trial was stopped if the mouse did not dig within 3 min in the testing cage. Stopped trials were uncommon $(<3 \%$ of all trials), and they occurred during the SD. A criterion of eight consecutive correct trials was required to complete each test. Reversal trials consisted of reversing the rewarded cue with the unrewarded cue in the exemplar pair. The WT and Plaur/HGF cohorts were 11 mice; for the other genotypes, 13 mice were tested. All mice were adult males, from 3 to 6 months of age, which were killed shortly after testing, at $4-7$ months of age. Data are reported as the mean number of trials to criterion \pm SEM. A two-way ANOVA was used to determine statistical significance between groups and discriminations, followed by Newman-Keuls post hoc analysis using the Statistica software package (Statsoft). Statistical significance was considered as $p<0.05$, and denoted by asterisks.

\section{Results}

\section{HGF/SF levels alter forebrain interneuron numbers}

Immunohistochemistry for $\mathrm{PV}\left(\mathrm{PV}^{+}\right)$shows a marked decrease in OFC neurons in the Plaur mouse (Fig. 1). Comparison of total $\mathrm{PV}^{+}$cells in the OFC demonstrates a main effect of genotype $\left(F_{(3,10)}=4.50, p=0.03\right)$. The number of $\mathrm{PV}^{+}$cells in the Plaur mice is $\sim 36 \%$ of WT cells [Plaur: $4346 \pm 1090$ cells (Fig. 1C,E), WT: $11,965 \pm 1675$ (Fig. $1 A, E), p=0.03$ ]. The number of OFC $\mathrm{PV}^{+}$cells in the HGF mice $(10,379 \pm 1568)$ (Fig. $\left.1 B, E\right)$ is similar to WT mice ( $p=0.77$ ). Increased postnatal HGF/SF expression in the Plaur mice eliminates the deficit observed in Plaur (Fig. $1 D, E)$, and the number of $\mathrm{PV}^{+}$cells in the Plaur/HGF mice $(10,885 \pm 1413)$ is similar to WT mice $(p=0.65)$. The volumes of the OFC regions were similar in all genotypes $\left(F_{(3,10)}=0.72\right.$, $p=0.56)$. In all mice, the distributions of $\mathrm{PV}^{+}$cells are similar to WT mice. In summary, the deficit of $\mathrm{PV}^{+}$interneurons in the Plaur mice was corrected by the postnatal addition of HGF/SF, as shown in the Plaur/HGF mice.

Forebrain GABAergic interneurons arise from the developing basal ganglia and the deficit in cerebral cortical interneurons in 

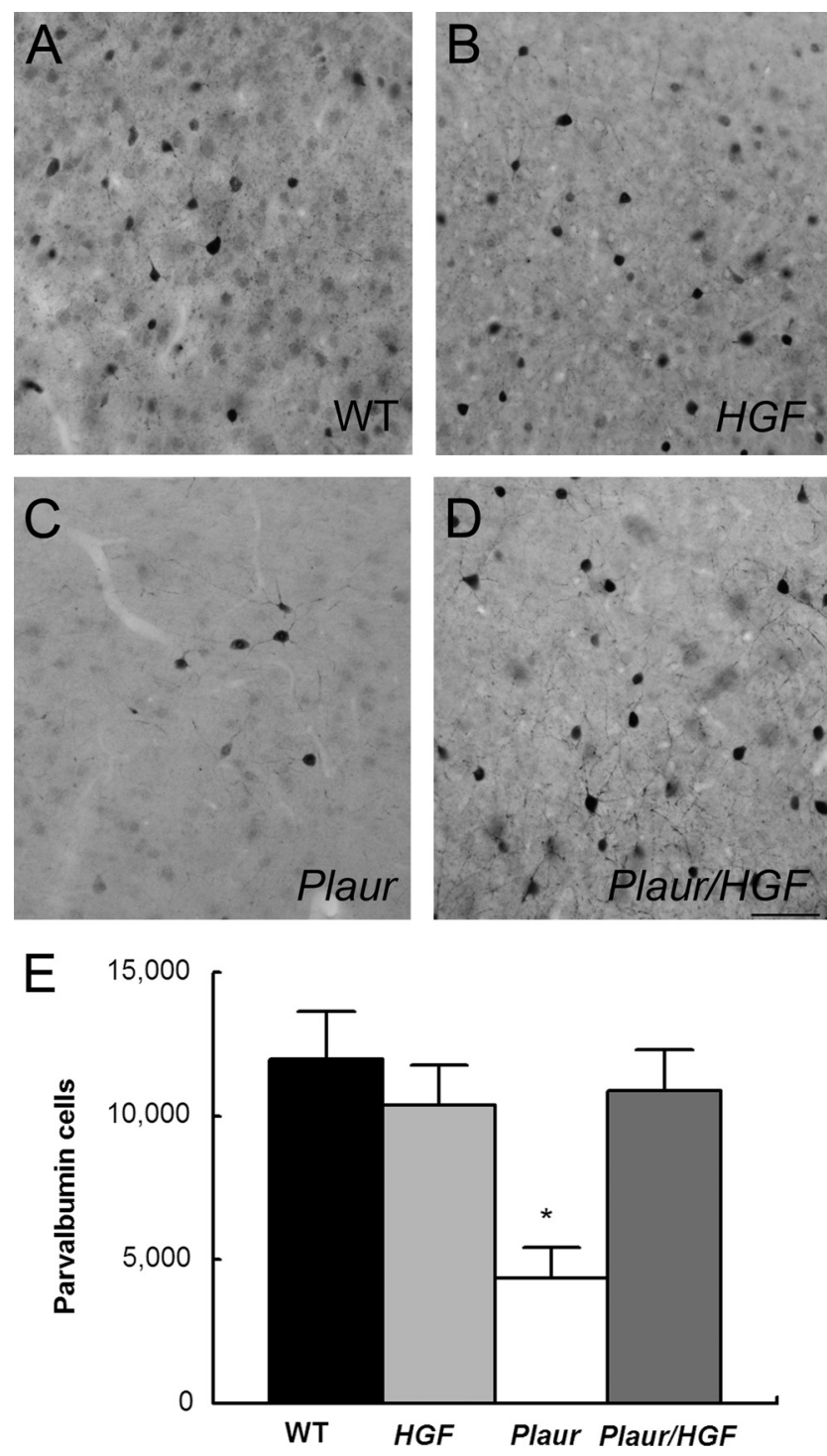

Figure 1. HGF/SF levels affect the number of GABAergic neurons in OFC. $A-D$, Immunohistochemistry of PV cells in OFC of adult WT (A), HGF (B), Plaur ( $(\boldsymbol{C}$, and Plaur/HGF mice (D). Scale bar, $200 \mu \mathrm{m} . \boldsymbol{E}$, The numbers of $\mathrm{PV}^{+}$cells were stereologically counted in orbital frontal cortex. Each bar represents $n \geq 3$, with error bars denoting the SEM. The PV ${ }^{+}$cells were severely decreased in the Plaur mice. Overexpressing HGF/SF increases the number of interneuron as compared to WT mice. In the HGF mice, $\mathrm{PV}^{+}$cells are similar to WT littermates. An asterisk denotes statistical significance as compared to WT mice $(p<0.05)$.

the Plaur mice suggested that other areas may have similar deficiencies. The anatomical studies were restricted to areas known to interact with the OFC to modulate behavior. Neurons in the OFC share reciprocal connections with the basal lateral amygdala. Previously the numbers of GABAergic (GAD67-expressing) neurons in the basal lateral amygdala were reported to be unchanged in the Plaur mouse as compared to WT (Eagleson et al., 2005). Last, the interneuron profiles in the striatum were examined in the mouse cohort. Figure 2 shows an apparent decrease in the number of $\mathrm{PV}^{+}$cells in the Plaur mouse $(A)$, which appears to be restored in the Plaur/HGF mice $(D)$. The WT and HGF mice displayed similar $\mathrm{PV}^{+}$cells. Stereological counts confirm these observations (Fig. $2 E$ ), with an effect of genotype $\left(F_{(3,9)}=22.10\right.$, $p<0.0001)$. The WT $(34,620 \pm 1129$ cells $), H G F(41,354 \pm$ $3475)$, and Plaur/HGF mice $(29,651 \pm 5204)$ had similar numbers of cells, whereas the Plaur mice had a $70 \%$ decrease
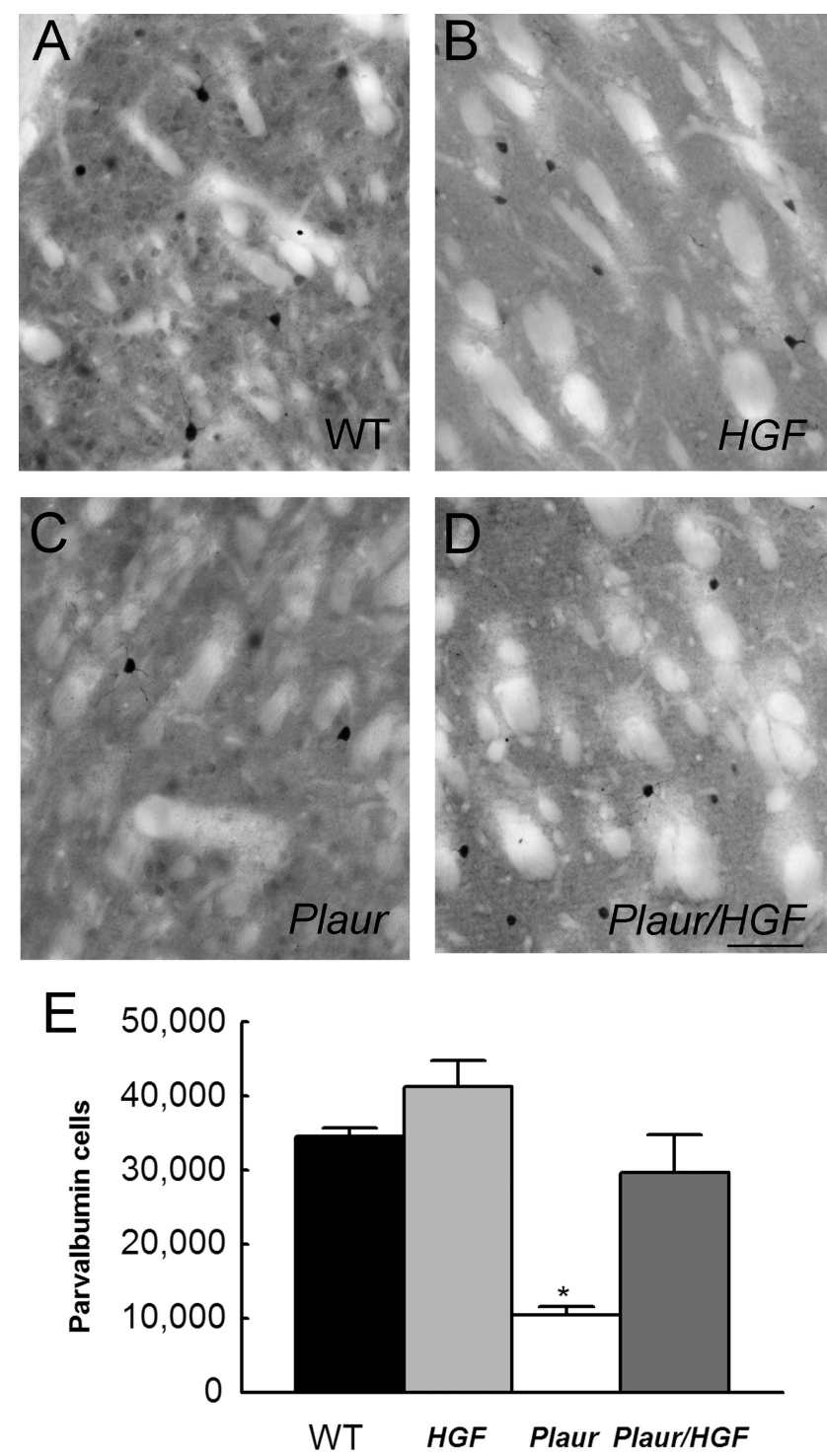

Figure 2. Striatal interneuron number is dependent upon Plaur and HGF.A-D, Immunohistochemistry of $\mathrm{PV}^{+}$cells in the dorsal striatum of adult WT $(\boldsymbol{A}), \operatorname{HGF}(\boldsymbol{B})$, Plaur (C), and Plaur/ HGF (D) mice. Scale bar, $250 \mu \mathrm{m}$. $\boldsymbol{E}$, Estimation of the $\mathrm{PV}^{+}$cells shows decreased numbers in the Plaur mice and a partial restoration of cell numbers in the Plaur/HGF mice. Each bar represents $n \geq 3$ mice, with error bars denoting the SEM. An asterisk denotes statistical significance as compared to WT mice $(p<0.05)$.

$(10,444 \pm 1156, p<0.001)$. Estimates of striatal volumes were similar in all genotypes $\left(F_{(3,9)}=2.07, p=0.17\right)$. The addition of $\mathrm{HGF} / \mathrm{SF}$ in the Plaur/HGF mice corrected the $\mathrm{PV}^{+}$interneuron deficit in the striatum.

\section{Reversal learning is correlated with GABAergic} interneuron number

Previously, we have shown that reversal learning in mice, like in rats and primates, is mediated through the OFC region (Bissonette et al., 2008). We tested all four genotypes of mice using the same paradigm: a series of training of compound discriminations with intradimensional shifts followed by a final reversal problem (Fig. 3; for all discriminations, see supplemental Fig. S2, available at www.jneurosci.org as supplemental material). ANOVA demonstrated an effect of task $\left(F_{(6,323)}=21.56, p<0.0001\right)$ and interaction of task $\times$ genotype $\left(F_{(18,323)}=60.55, p<0.004\right)$. There was no effect of genotype $\left(F_{(3,323)}=2.25, p=0.082\right)$, as all four 


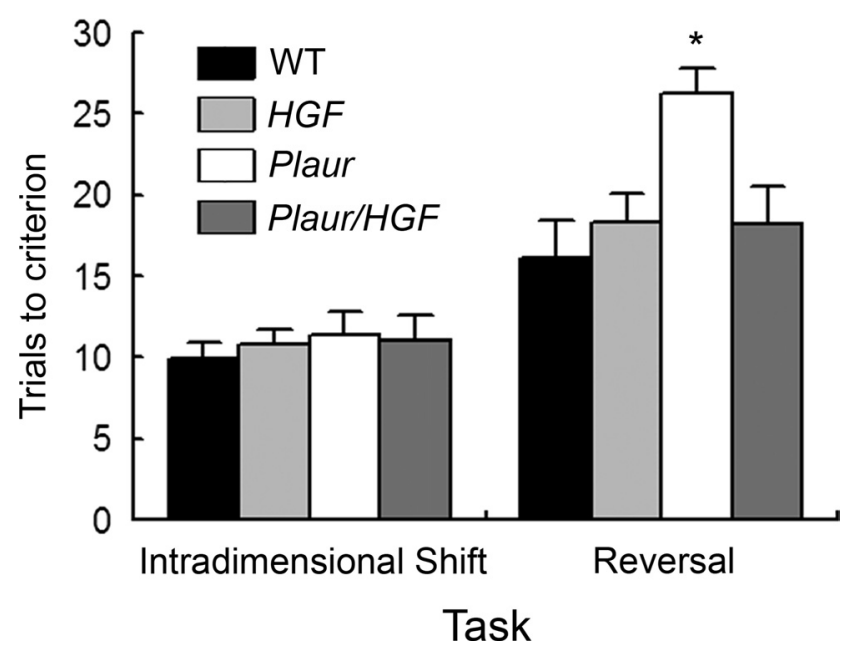

Figure 3. Impaired reversal learning in Plaur mice is recovered with addition of HGF/SF. All mice performed similarly on the compound odor and texture discrimination task. The reversal task was more difficult for all groups, as shown by the increase in trials to criterion. The Plaur mice were impaired on the reversal task, as compared to WT, but deficit was recovered in the Plaur/HGF group. The HGF mice performed similarly to the WT group. An asterisk denotes statistical significance as compared to WT mice $(p<0.05)$.

groups performed similarly on the training tasks. The Plaur mice learned the intradimensional shift discriminations similarly to the WT mice ( $p>0.86$ ) (supplemental Fig. S2, available at www. jneurosci.org as supplemental material). For the final intradimensional shift discrimination, the Plaur mice completed the task with the same number of trials $(11.4 \pm 1.4)$ as the WT mice $(9.9 \pm 1.0, p>0.99)$ (Fig. 3). For the reversal discriminations, the Plaur animals required significantly more trials $(26.3 \pm 1.5)$ to learn the reversal task than WT mice $(16.2 \pm 2.3, p<0.0001)$. The Plaur mice with the GABAergic interneuron deficits demonstrated impaired reversal learning.

The HGF and Plaur/HGF mice were also tested on the reversal task. The presence of the HGF allele did not affect the ability of the mice to solve the problem, as HGF mice (10.9 \pm 0.9 trials) and Plaur/HGF mice $(11.0 \pm 2.3$ trials $)$ performed similar to WT mice $(p>0.92)$. On the reversed discriminations, the HGF (18.3 \pm 1.8 trials) and Plaur/HGF mice (18.2 \pm 2.4 trials) performed similarly to WT mice ( $p>0.45)$. The Plaur/HGF mice performed the reversal discriminations differently than their Plaur littermates $(p<0.001)$. The addition of HGF/SF to the Plaur mouse reduced the number to trials needed to reach criterion and restored the problem solving ability to WT levels. The improved performance of the Plaur/HGF mouse on the reversal testing corresponds to the amelioration of the GABAergic interneuron deficit in the OFC and striatum.

\section{Discussion}

The present study demonstrates that reversal learning is dependent upon proper numbers of GABAergic interneurons. Mice with a null mutation in Plaur have reduced numbers of $\mathrm{PV}^{+}$GABAergic local interneurons in the OFC and striatal regions, with normal interneurons in the $\mathrm{BLA}$. The $\mathrm{PV}^{+}$interneuron populations in the OFC and striatum along with the reversal learning impairment are restored with postnatal HGF/SF supplementation in the Plaur/HGF mice. These results show that GABAergic local circuitry in the OFC and striatum are critical for modulating behavioral flexibility and that birth defects can be corrected by replenishing crucial growth factors.
Through lesion studies, specific forms of cognitive flexibility are attributed to distinct brain regions and circuits. Reversal learning in primates and rodents is dependent upon intact OFC and striatum (Dias et al., 1996b; McAlonan and Brown, 2003; Schoenbaum et al., 2003; Kim and Ragozzino, 2005; Bissonette et al., 2008). Animals with neurotoxic lesions to the OFC acquire discriminations normally but require $\sim 40 \%$ more trials to switch responding when reward contingencies are reversed. In comparison, the Plaur mice needed $62 \%$ more trials to complete the test. The postnatal intervention of HGF/SF in the Plaur/HGF mouse allows the GABAergic interneurons to survive (Bae et al., 2005, 2010), and thus the resulting OFC neural circuitry is able to perform the reversal task similar to wild-type mice.

Information from the OFC flows through the basal ganglia, and lesions in the human, primate, and rat impair reversal learning (Bellebaum et al., 2008; Clarke et al., 2008; Tait and Brown, 2008). Studies in monkeys report that lesions in the striatum yield reversal learning deficits similar to lesions to the OFC, but the response to feedback differs, suggesting a hierarchy in the processing of information (Clarke et al., 2008). The dorsal striatum has a major role in reward prediction (Seymour et al., 2007), whereas the OFC represents both positive and negative outcome expectancies (Schoenbaum et al., 1998; O'Doherty et al., 2001). Damage to the ventral striatum has often been reported to alter reversal learning in primates and rodents (Cools et al., 2002; Tait and Brown, 2008). However, experimental ventral lesions have the potential to simultaneously compromise the dorsomedial striatum, which is the division involved in cognition. In fact, in patients, lesions in the dorsal striatum caused the greatest impairments (Seymour et al., 2007; Bellebaum et al., 2008). In addition, current reports in primates and rats support the role of the dorsomedial striatum in reversal learning (Ragozzino, 2007; Clarke et al., 2008).

The anatomical deficits presented in this study affect both dorsal striatum and OFC areas, because the OFC interneurons arise in the striatum during embryogenesis and the Plaur mutation alters both GABAergic interneuron populations. In the striatum, the $\mathrm{PV}^{+}$interneurons receive direct inputs from different cortical regions, including the OFC, and synapse on the medium spiny output neurons. Loss of $\mathrm{PV}^{+}$neurons in the striatum may lead to rerouting of the OFC afferents to directly synapse on the medium spiny neurons or reduce the number of OFC inputs. The present system cannot dissociate the individual contributions of the OFC and striatum with regards to the deficit in reversal learning. Nonetheless, it is likely that human neurological disorders, such as obsessive compulsive disorder (OCD) and schizophrenia, have altered circuitry in multiple regions due to developmental perturbations. In the case of the Plaur mice, the anatomy in each region was restored after postnatal supplementation with $\mathrm{HGF} / \mathrm{SF}$ indicating a possible candidate for therapy.

The OFC and striatal interneurons are specified in a division of the ganglionic eminence that is found medially, whereas the BLA interneurons are derived from a more caudal division (Nery et al., 2002). The Plaur mutation and changes in HGF/SF levels specifically influence the neurons derived from the medial ganglionic eminence (Eagleson et al., 2005; Martins et al., 2007; Bae et al., 2010) (also G. J. Martins and E. M. Powell, unpublished data). Finally, the interneuron deficits in the cerebral cortex were more severe in rostral forebrain regions and not present in occipital areas (Powell et al., 2003; Eagleson et al., 2005). One possible explanation for this phenotype is the gradient of HGF/SF expression, high caudal to low rostral (Achim et al., 1997), leading to subthreshold HGF/SF levels in frontal areas in the Plaur mice, but 
having little effect on the occipital pole. The anatomical deficit in the Plaur mice reflects the reduced HGF/SF expression and can be corrected by exogenous perinatal HGF/SF supplementation (Bae et al., 2010).

The anatomy of the HGF mouse appeared to be grossly normal, indicating that exogenous HGF/SF did not alter postnatal development. Based on the roles of HGF/SF in forebrain ontogeny (Achim et al., 1997; Thewke and Seeds, 1999), we suggest that it may be involved in cell survival and possibly maturation and synaptogenesis. In another study, HGF/SF levels were measured in the four groups of mice, and the supplementation through astrocyte promoter in mice with the HGF allele was detected at birth in both the HGF and Plaur/HGF mice (Bae et al., 2010). During embryonic development, human HGF (from the GfapHGF transgene) was not detected in the HGF and Plaur/HGF mice by ELISA (data not shown). While cortical development continues into adulthood, the timing of the human HGF expression corresponded to astrocyte postnatal development. The exogenous HGF/SF most likely affects glial ontogeny, synaptogenesis, and survival. The Plaur mouse demonstrated a $40 \%$ decrease in HGF/SF levels in the cerebral cortex at birth and in the adult, whereas HGF/SF levels in the Plaur/HGF mouse was similar to the WT mouse at both ages. The anatomical counts are based on PV immunoreactivity, and PV levels may be regulated by HGF/SF. However, immunohistochemistry for GABA, glutamic acid decarboxylase (Gad67), and perineural nets revealed similar results [Bae et al. (2010) and data not shown], indicating loss of the GABAergic cells. The striking anatomical and behavioral similarities in the WT and Plaur/HGF mice indicate that the Plaur phenotype may be due in part to a HGF/SF deficiency.

The interneuron deficit of the Plaur mouse is not evident in the Plaur/HGF mouse. Yet, multiple other cell types are likely affected by the loss of Plaur, particularly in regards to synaptic connectivity. In the cerebral cortex, the PV subpopulation of GABAergic interneurons seems to be uniquely affected, as the numbers of somatostatin- and calretinin-expressing cells are the same in all genotypes (Bae et al., 2010). In addition, multiple other factors may be involved (Berghuis et al., 2004; Galloway et al., 2008). The increased levels of HGF/SF in the Plaur/HGF mice may be sufficient to overcome many deficits and mask others. Future studies will examine the interactions of multiple growth factors in establishing and maintaining functional forebrain circuitry.

Neurological disorders including schizophrenia and epilepsy have similarities in loss of GABAergic inhibition (Benes et al., 1991; Beasley and Reynolds, 1997; Avoli et al., 1999; Baulac et al., 2001; Lewis et al., 2005). In our experiments, through manipulating development of GABAergic interneurons, we were able to show selective anatomical deficits that alter specific circuits with parallel behavioral dysfunction. The agreement of behavioral alterations with changes in GABAergic tone in specific forebrain structures indicates that shifting away from an optimal level of GABA yields cognitive impairments. Additional studies should be done to demonstrate whether the recovery of the $\mathrm{PV}^{+}$interneuron deficit by HGF/SF is specific to the OFC and striatum or more general throughout the forebrain. Along the same lines, the behavioral analysis in the Plaur/HGF mice is a broad measurement of function. Future studies with electrophysiological recordings in awake behaving mice should provide more detailed information about the circuits in the Plaur and HGF mutants.

\section{References}

Achim CL, Katyal S, Wiley CA, Shiratori M, Wang G, Oshika E, Petersen BE, Li JM, Michalopoulos GK (1997) Expression of HGF and cMet in the developing and adult brain. Brain Res Dev Brain Res 102:299-303.

Anderson SA, Qiu M, Bulfone A, Eisenstat DD, Meneses J, Pedersen R, Rubenstein JL (1997) Mutations of the homeobox genes Dlx-1 and Dlx-2 disrupt the striatal subventricular zone and differentiation of late born striatal neurons. Neuron 19:27-37.

Anderson SA, Marín O, Horn C, Jennings K, Rubenstein JL (2001) Distinct cortical migrations from the medial and lateral ganglionic eminences. Development 128:353-363.

Avoli M, Bernasconi A, Mattia D, Olivier A, Hwa GG (1999) Epileptiform discharges in the human dysplastic neocortex: in vitro physiology and pharmacology. Ann Neurol 46:816-826.

Bae M, Harmon MCJ, Mars WM, Michalopoulos GK, Achim C, Powell EM (2005) Critical roles for uPAR and HGF/SF in brain development and epilepsy. Thromb Haemo 93:A2.

Bae MH, Bissonette GB, Mars WM, Michalopoulos GK, Achim C, Depireux DA, Powell EM (2010) Hepatocyte growth factor (HGF) modulates GABAergic inhibition and seizure susceptibility. Exp Neurol 221: $129-135$.

Baulac S, Huberfeld G, Gourfinkel-An I, Mitropoulou G, Beranger A, Prud'homme JF, Baulac M, Brice A, Bruzzone R, LeGuern E (2001) First genetic evidence of $\mathrm{GABA}(\mathrm{A})$ receptor dysfunction in epilepsy: a mutation in the gamma2-subunit gene. Nat Genet 28:46-48.

Beasley CL, Reynolds GP (1997) Parvalbumin-immunoreactive neurons are reduced in the prefrontal cortex of schizophrenics. Schizophr Res 24:349-355.

Bellebaum C, Koch B, Schwarz M, Daum I (2008) Focal basal ganglia lesions are associated with impairments in reward-based reversal learning. Brain 131:829-841.

Benes FM, McSparren J, Bird ED, SanGiovanni JP, Vincent SL (1991) Deficits in small interneurons in prefrontal and cingulate cortices of schizophrenic and schizoaffective patients. Arch Gen Psychiatry 48:996-1001.

Berghuis P, Dobszay MB, Sousa KM, Schulte G, Mager PP, Härtig W, Görcs TJ, Zilberter Y, Ernfors P, Harkany T (2004) Brain-derived neurotrophic factor controls functional differentiation and microcircuit formation of selectively isolated fast-spiking GABAergic interneurons. Eur J Neurosci 20:1290-1306.

Bissonette GB, Martins GJ, Franz TM, Harper ES, Schoenbaum G, Powell EM (2008) Double dissociation of the effects of medial and orbital prefrontal cortical lesions on attentional and affective shifts in mice. J Neurosci 28:11124-11130.

Brigman JL, Bussey TJ, Saksida LM, Rothblat LA (2005) Discrimination of multidimensional visual stimuli by mice: intra- and extradimensional shifts. Behav Neurosci 119:839-842.

Clarke HF, Robbins TW, Roberts AC (2008) Lesions of the medial striatum in monkeys produce perseverative impairments during reversal learning similar to those produced by lesions of the orbitofrontal cortex. J Neurosci 28:10972-10982.

Cobos I, Calcagnotto ME, Vilaythong AJ, Thwin MT, Noebels JL, Baraban SC, Rubenstein JL (2005) Mice lacking Dlx1 show subtype-specific loss of interneurons, reduced inhibition and epilepsy. Nat Neurosci 8:1059-1068.

Colacicco G, Welzl H, Lipp HP, Würbel H (2002) Attentional set-shifting in mice: modification of a rat paradigm, and evidence for strain-dependent variation. Behav Brain Res 132:95-102.

Cools R, Clark L, Owen AM, Robbins TW (2002) Defining the neural mechanisms of probabilistic reversal learning using event-related functional magnetic resonance imaging. J Neurosci 22:4563-4567.

Dewerchin M, Nuffelen AV, Wallays G, Bouché A, Moons L, Carmeliet P, Mulligan RC, Collen D (1996) Generation and characterization of urokinase receptor-deficient mice. J Clin Invest 97:870-878.

Dias R, Robbins TW, Roberts AC (1996a) Primate analogue of the Wisconsin Card Sorting Test: effects of excitotoxic lesions of the prefrontal cortex in the marmoset. Behav Neurosci 110:872-886.

Dias R, Robbins TW, Roberts AC (1996b) Dissociation in prefrontal cortex of affective and attentional shifts. Nature 380:69-72.

Eagleson KL, Bonnin A, Levitt P (2005) Region- and age-specific deficits in gamma-aminobutyric acidergic neuron development in the telencephalon of the uPAR(-/-) mouse. J Comp Neurol 489:449-466.

Ferrer I, Oliver B, Russi A, Casas R, Rivera R (1994) Parvalbumin and 
calbindin-D28k immunocytochemistry in human neocortical epileptic foci. J Neurol Sci 123:18-25.

Galloway EM, Woo NH, Lu B (2008) Persistent neural activity in the prefrontal cortex: a mechanism by which BDNF regulates working memory? Prog Brain Res 169:251-266.

Hashimoto T, Arion D, Unger T, Maldonado-Avilés JG, Morris HM, Volk DW, Mirnics K, Lewis DA (2008) Alterations in GABA-related transcriptome in the dorsolateral prefrontal cortex of subjects with schizophrenia. Mol Psychiatry 13:147-161.

Howard CV, Reed MG (1998) Unbiased stereology, Ed 1. New York: Garland Science/BIOS Scientific Publishers.

Kim J, Ragozzino ME (2005) The involvement of the orbitofrontal cortex in learning under changing task contingencies. Neurobiol Learn Mem 83:125-133.

Letinic K, Zoncu R, Rakic P (2002) Origin of GABAergic neurons in the human neocortex. Nature 417:645-649.

Lewis DA, Hashimoto T, Volk DW (2005) Cortical inhibitory neurons and schizophrenia. Nat Rev Neurosci 6:312-324.

Marin O, Anderson SA, Rubenstein JL (2000) Origin and molecular specification of striatal interneurons. J Neurosci 20:6063-6076.

Martins GJ, Plachez C, Powell EM (2007) Loss of embryonic MET signaling alters profiles of hippocampal interneurons. Dev Neurosci 29:143-158.

McAlonan K, Brown VJ (2003) Orbital prefrontal cortex mediates reversal learning and not attentional set shifting in the rat. Behav Brain Res 146:97-103.

Nery S, Fishell G, Corbin JG (2002) The caudal ganglionic eminence is a source of distinct cortical and subcortical cell populations. Nat Neurosci 5:1279-1287.

O’Doherty J, Kringelbach ML, Rolls ET, Hornak J, Andrews C (2001) Abstract reward and punishment representations in the human orbitofrontal cortex. Nat Neurosci 4:95-102.

Paxinos G, Franklin KBJ (2001) The mouse brain in stereotaxic coordinates, Ed 2. San Diego: Academic.

Porter BE, Brooks-Kayal A, Golden JA (2002) Disorders of cortical development and epilepsy. Arch Neurol 59:361-365.

Powell EM, Mars WM, Levitt P (2001) Hepatocyte growth factor/scatter factor is a motogen for interneurons migrating from the ventral to dorsal telencephalon. Neuron 30:79-89.

Powell EM, Campbell DB, Stanwood GD, Davis C, Noebels JL, Levitt P (2003) Genetic disruption of cortical interneuron development causes region- and GABA cell type-specific deficits, epilepsy, and behavioral dysfunction. J Neurosci 23:622-631.

Ragozzino ME (2007) The contribution of the medial prefrontal cortex, orbitofrontal cortex, and dorsomedial striatum to behavioral flexibility. Ann N Y Acad Sci 1121:355-375.

Schoenbaum G, Chiba AA, Gallagher M (1998) Orbitofrontal cortex and basolateral amygdala encode expected outcomes during learning. Nat Neurosci 1:155-159.

Schoenbaum G, Setlow B, Nugent SL, Saddoris MP, Gallagher M (2003) Lesions of orbitofrontal cortex and basolateral amygdala complex disrupt acquisition of odor-guided discriminations and reversals. Learn Mem 10:129-140.

Seymour B, Daw N, Dayan P, Singer T, Dolan R (2007) Differential encoding of losses and gains in the human striatum. J Neurosci 27:4826-4831.

Stork O, Ji FY, Kaneko K, Stork S, Yoshinobu Y, Moriya T, Shibata S, Obata K (2000) Postnatal development of a GABA deficit and disturbance of neural functions in mice lacking GAD65. Brain Res 865:45-58.

Tait DS, Brown VJ (2008) Lesions of the basal forebrain impair reversal learning but not shifting of attentional set in rats. Behav Brain Res 187:100-108.

Tamminga C, Hashimoto T, Volk DW, Lewis DA (2004) GABA neurons in the human prefrontal cortex. Am J Psychiatry 161:1764.

Thewke DP, Seeds NW (1999) The expression of mRNAs for hepatocyte growth factor/scatter factor, its receptor c-met, and one of its activators tissue-type plasminogen activator show a systematic relationship in the developing and adult cerebral cortex and hippocampus. Brain Res 821:356-367.

West MJ (1999) Stereological methods for estimating the total number of neurons and synapses: issues of precision and bias. Trends Neurosci 22:51-61.

Wonders CP, Anderson SA (2006) The origin and specification of cortical interneurons. Nat Rev Neurosci 7:687-696. 